\title{
Contrabando de tabaco \\ en la factoría de Durango, \\ 1764-1824
}

\section{Edgar Bueno Hurtado ${ }^{1}$ \\ edgarmenos2424@hotmail.com DOI: http://orcid.org/0000-0001-7589-027X}

Tolbacco smuggling in the Factoría de

Durango, 1778-1812

\section{Resumen}

Con el fin de aumentar los ingresos la metrópoli decretó en Nueva España el estanco del tabaco; es decir, un monopolio sobre su siembra, manufactura y venta. Para cumplir con su objetivo, creó la Renta del tabaco que se caracterizó por tener una estructura centralizada en donde administraciones regionales conocidas como factorías estarían subordinadas a una administración general ubicada en la Ciudad de México. El objetivo de este estudio es, mediante el análisis de los juicios de comiso, analizar el contrabando de tabaco en la factoría de Durango, aquel comercio ilícito que la misma administración tenía la obligación de perseguir pero que no lograba con mucho éxito.

Palabras clave: Contrabando, tabaco, monopolio, factoría, Durango.

\section{Abstract}

In order to increase revenues, the monarchy of Spain decreed in the New Spain the "estanco del tabaco", that is, a monopoly on its sowing, manufacture and sale. To achieve its objective, the Renta del tabaco was created, which was characterized by having a centralized structure where regional administrations known as fac- torías would be subordinated to a general administration located in Mexico City. The objective of this study is, through the analysis of confiscation lawsuits, analyze the smuggling of tobacco in the factory in Durango, that illicit trade that the same administration had the obligation to pursue but did not achieve with success.

Keywords: Smuggling, tobacco, monopoly, factoría, Durango.

1 Universidad Juárez del Estado de Durango, México.

Calle Constitución 404, C. P. Zona Centro, Durango, Durango, México. 


\section{Introducción}

La metrópoli decretó mediante un ordenamiento real emitido en 1764, el estanco del tabaco en la Nueva España, cuyo objetivo primordial fue el de aumentar las recaudaciones de la Corona, por lo que, en teoría, las ganancias derivadas del estanco debían remitirse íntegramente a España. Para esto se diseñó un monopolio sobre la siembra, manufactura y venta de los diversos productos derivados del tabaco. La administración del monopolio quedó directamente en manos del Estado a través de la Renta del tabaco.

El monopolio ha llamado la atención de los historiadores por las grandes ganancias que generó. Este, ha sido referido como el mayor éxito fiscal de la Corona en la Nueva España (Ayluardo, 2010, p. 320) y como una de las herramientas fiscales más estratégicas dentro de las finanzas imperiales (Marichal, 1999, p. 76). En este sentido, han surgido estudios enfocados exclusivamente en el estanco, autores como David Lorne Mcwaters, Susan Deans-Smith y Guillermo Céspedes del Castillo han brindado un amplio panorama sobre la organización de la Renta, su lógica institucional, así como el aspecto cuantitativo.

La Renta del tabaco estuvo regulada por la ordenanza de la Real Renta del Tabaco, expedida en 1768, que tenía como objetivo principal "dar reglas generales que sirvan para el régimen de la propia Renta en todo el reino, y por ella se instruyan todos y cada uno de los dependientes de las obligaciones respectivas a sus destinos" (Fonseca \& Urrutia, 1978, p. 439). A partir de la ordenanza se podría definir a la Renta del tabaco como una gran organización burocrática distribuida a lo largo del territorio novohispano a través de administraciones regionales conocidas como factorías, con su centro en la Ciudad de México, dirigido por un cuerpo de oficiales reales con el director general a la cabeza (McWatters, 1979, p. 2).

Las funciones de toda esta burocracia revelaban la lógica con la que se organizó el estanco, donde se mostraba a una Renta guiada por un esfuerzo de centralización, permitiendo un enlace de operación local y "nacional" que tenía como propósitos comercializar productos derivados del tabaco, procurar la supervisión de los empleados y conseguir una efectiva recaudación de los ingresos generados en toda la Nueva España.

La factoría de Durango fue la administración del septentrión novohispano que más recursos enviaba a la administración central, por lo que visto desde el objetivo recaudatorio de la Corona y respecto de la gran mayoría de las otras administraciones regionales, puede decirse que fue una factoría exitosa. Sin embargo, no puede ignorarse que paralelamente al comercio monopolizado por la Renta, existió un comercio clandestino, 
el cual era perseguido por las autoridades de la Renta del tabaco. Analizar esta ilegalidad es el objetivo de la presente pesquisa.

$\mathrm{El}$ estudio de este contrabando es relevante porque explica parte del funcionamiento de la Renta del tabaco, ya que su persecución estuvo regulada por dicha institución. Para entender la relevancia del contrabando y la manera en que se perseguía, el trabajo se divide en tres apartados. El primero explica la lógica mediante la cual la Renta del tabaco pretendía monopolizar; también se analizan las distinciones entre las administraciones regionales para, de ese modo, situar la importancia y las particularidades de la factoría de Durango. En el segundo se aborda el consumo de tabaco en los estanquillos de la factoría, donde se analizan las tendencias de consumo de los habitantes desde un punto de vista oficial, es decir, desde el comercio monopolizado por la Renta. Por último, mediante el análisis de los juicios de comiso, se estudia propiamente el contrabando de tabaco. Estos procesos muestran unas tendencias de consumo distintas a las que se observan desde el punto de vista de las ventas legales.

\section{La Renta del tabaco en la factoría de Durango}

Con los borbones al mando en la metrópoli, se iniciaron en la Nueva España una serie reformas administrativas que pretendían lograr un control más efectivo sobre sus colonias para, entre otras cosas, lograr extraer mayores riquezas. Las llamadas reformas borbónicas se iniciaron a principios del siglo XVIII, pero tuvieron su auge más enérgico a partir de 1764, año en el que se ordenó el estanco del tabaco. El monopolio fue ideado exclusivamente para generar mayores ingresos para la Corona, por lo que el estanco se consideró como un ramo remisible; es decir, que su finalidad fue la de remitir sus ganancias íntegramente a España. El monopolio nunca pudo consolidarse efectivamente como un "ramo remisible", ya que cargó con responsabilidades más amplias como el envío de situados. Sin embargo, toda la estructura administrativa de la Renta del tabaco estaba encaminada a extraer las ganancias de las ventas generadas dentro de la Nueva España para dirigirlas a una administración central, también referida como dirección general, y de ahí enviarlas a la metrópoli.

Para que la Renta pudiera conseguir sus fines era necesario reestructurar el comercio de tabaco preexistente, lo que provocó un rechazo por parte de la población novohispana, a pesar de que no existió una élite capaz de oponerse a las autoridades virreinales y sus intenciones de monopolizar el comercio del tabaco (Deans-Smith, 2014, p. 74). La gran cantidad de modestos tabaqueros, -quienes en muchas ocasiones dependían de la venta de los diversos productos de tabaco para su sustento- fueron los que hi- 
cieron titubear a las autoridades para establecer el estanco. ${ }^{2}$ El rechazo de los comerciantes hacia el monopolio fue finalmente superado (o al menos sobrellevado lo suficiente para lograr implantar el monopolio en todo el territorio) mediante la estrategia de incluir a los tabaqueros en el comercio.

El monopolio abarcó la siembra, manufactura y venta del tabaco. La siembra fue relegada hacia algunas regiones del actual estado de Veracruz, la manufactura se realizó en fábricas de puros y cigarros que la misma Renta estableció, y por toda la Nueva España se establecieron un sin número de los denominados "estanquillos", que fueron los únicos centros autorizados para la venta de puros y cigarros. Para regular estas actividades, en 1768 surgió la ordenanza de la Real Renta del tabaco, que fue el principal ordenamiento de la Renta del tabaco. Allí se estableció la estructura de la Renta y las pautas a seguir por su burocracia.

La ordenanza de 1768 diseñó una administración central al mando de unidades regionales (conocidas como factorías), que a su vez tendrían bajo su mando a los partidos agregados y estos a los fielatos agregados. Mediante esta estructura, la Renta se organizó para distribuir el tabaco por todas sus administraciones y recoger de estas las ganancias respectivas y la cadena de subordinación le sirvió para vigilar a sus empleados.

La ordenanza catalogó como funcionarios de la administración o dirección general al director de la Renta, contador general, tesorero principal, fiel principal de almacenes generales de México y al oficial de libros de los almacenes generales. Las administraciones regionales cumplían con la función de extender el monopolio a lo largo de la Nueva España. Se distinguió como funcionarios de las factorías, a un factor administrador general de provincia, un contador de factoría general, al fiel administrador de los partidos agregados y al fiel de las tercenas en los fielatos.

A pesar de que la regulación esencial del estanco se emitió en 1768 , fue aproximadamente hasta 1778 cuando comenzó a ejercerse en la Nueva España. El rechazo de la población novohispana, aunado a la de por sí problemática monopolización de la siembra, manufactura y venta, provocó que el estanco demorara algunos años en afianzarse. Para 1778 ya se había determinado la división territorial de las administraciones regionales, se logró ejercer el control sobre la siembra, se encontraban en funcionamiento las fábricas y se logró abolir las cigarrerías privadas para dar entrada a los estanquillos. A partir de entonces la reglamentación de 1768 comenzó a cobrar sentido y la dirección general en México se convirtió en el centro del monopolio en la Nueva España.

2 Las primeras propuestas para establecer el estanco provienen desde mediado del siglo XVII (Amerlinck, 1988, p. 105). 
La factoría de Durango dejó de cumplir con sus fines hasta 1812, cuando interrumpió su remisión de caudales a la dirección general en el contexto de la independencia. Algunas de las consecuencias fueron: la dislocación de los circuitos mercantiles, el resquebrajamiento de la autoridad central virreinal como consecuencia de la guerra y la presencia de partidas de insurgentes y gavillas de bandidos, así como el deterioro constante de los caminos que obstaculizaba el arribo de tabaco a las fábricas, en especial a la de la Ciudad de México (Hernández, 2011, p. 39). Se concluye que la administración regional conocida como factoría del tabaco de Durango estuvo en funciones en el periodo de 1778 a 1813.

La organización de la Renta se conformó -además de la administración central ubicada en la Ciudad de México- por diez factorías: Córdoba, Durango, Guadalajara, Mérida, Oaxaca, Puebla, Orizaba, Rosario, Valladolid y Veracruz. También se contó con cuatro administraciones independientes ubicadas en Coahuila, Mazapil, Monterrey y Santander (Deans-Smith, 2014, p. 108). Estas últimas no contaron con la estructura de una factoría; sin embargo, estaban subordinadas a la administración central y se les denominaba "independientes" porque rendían cuentas a través de su respectivo alcalde mayor y no de un factor (Céspedes, 1992, p. 138).

Respecto de las fábricas encargadas de trabajar las cosechas procedentes de las zonas autorizadas, en un principio se intentó que cada factoría contara con su propio centro manufacturero (McWatters, 1979, p. 99), obra que no pudo llevarse a cabo. Finalmente se establecieron seis fábricas: una en la administración central, otras en las factorías de Puebla, Oaxaca, Guadalajara y Orizaba; una ubicada en Querétaro, que fungió como auxiliar a la gran fábrica de México. ${ }^{3}$

En la Figura 1 se observa la lógica de funcionamiento de la Renta. Por jerarquía debe entenderse que la administración general de México era la autoridad máxima, seguida por las factorías o las gerencias independientes y, según fuera el caso, tendrían a su cargo los partidos y estos a su vez a los fielatos. En ese mismo orden se daba la distribución del tabaco y en un orden contrario -desde los fielatos hasta llegar a la administración central- se daba el envío de caudales, ya que muchos de los estanquillos estaban ubicados en poblados muy lejanos a la Ciudad de México. Las fábricas no generaron diferencias respecto de la lógica administrativa de las factorías, pero debe destacarse que aún entre las factorías hubo distinciones que provocaron que el envío de ganancias a la dirección general se diera dentro de un contexto distinto. $3 \begin{aligned} & \text { Esta última fue la encargada de abastecer a las factorías y administraciones indepen- } \\ & \text { dientes del septentrión novohispano. }\end{aligned}$ 


\section{Figura 1}

Jerarquía de la Renta del Tabaco

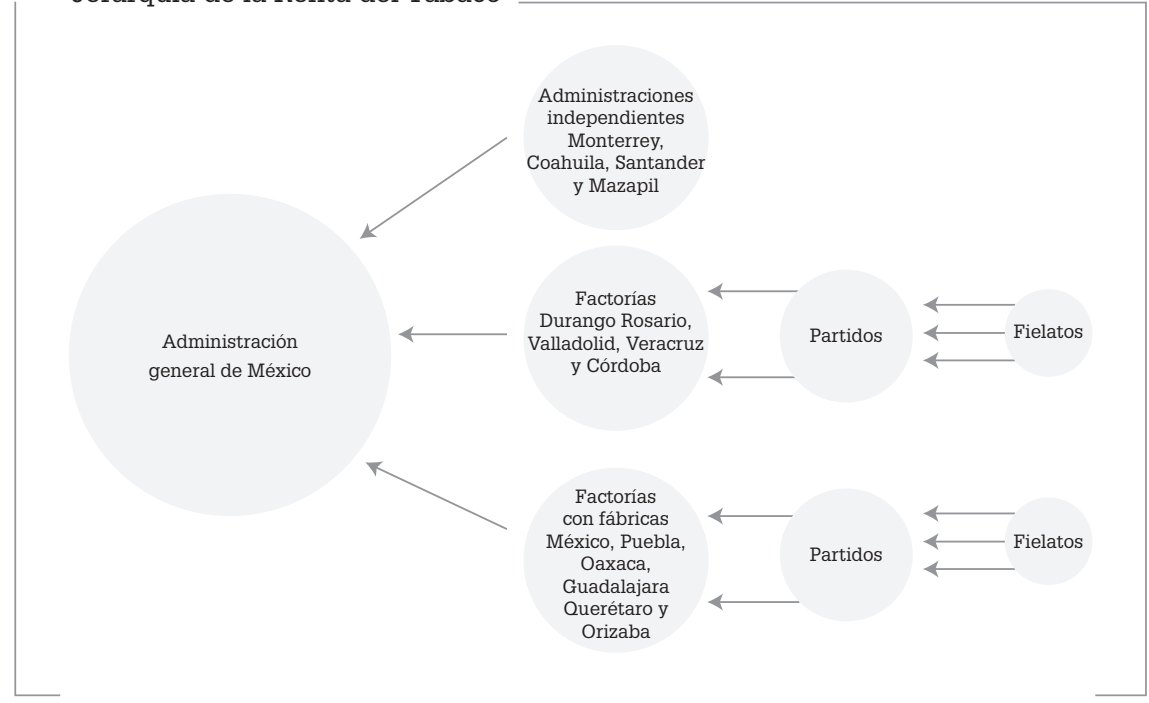

Fuente: Elaboración propia con base en la ordenanza de la Renta del tabaco de 1768 (Fonseca \& Urrutia, 1978, pp. 354-486).

Los "envíos de caudales" o remisiones, consistían en las ganancias que la factorías enviaban, una vez costeados sus gastos de operación, tales como el pago a empleados, compras del tabaco, pago de fletes, entre otros. La Tabla 1 ha sido publicada en el multicitado estudio de Susan Deans-Smith (2014), quien se basó en las contabilidades individuales de cada administración, la lista de las remisiones de las factorías y administraciones independientes a la dirección general. La tabla está organizada por periodos de cinco años, donde se muestra el promedio anual en cada quinquenio del envío de caudales desde todas las administraciones regionales a la dirección general. En la Tabla 1 se observa que la factoría de Durango se encuentra situada como la administración del septentrión novohispano que más generaba ganancias, aportando en promedio un siete por ciento del total del monopolio.

Como ya se mencionó, entre las administraciones regionales existieron distinciones que provocaban que el envío de caudales se diera en un contexto distinto. Los gastos de gestión, -además de la lógica de recaudación- eran diferentes en una administración independiente que en una factoría; también fueron distintos para una factoría que tenía a su cargo una fábrica respecto de la que no. A pesar de estas diferencias, las ganancias de la Renta dependían de las ventas logradas en los estanquillos. 


\section{Ta.bla 1}

\begin{tabular}{|c|c|c|c|c|c|c|c|}
\hline $\begin{array}{l}\text { Adminis- } \\
\text { tración* }\end{array}$ & $\begin{array}{c}1766- \\
1770\end{array}$ & $\begin{array}{l}1771- \\
1775\end{array}$ & $\begin{array}{l}1776- \\
1780\end{array}$ & $\begin{array}{l}1781- \\
1785\end{array}$ & $\begin{array}{l}1786- \\
1790\end{array}$ & $\begin{array}{l}1791- \\
1795\end{array}$ & $1796-1800$ \\
\hline México & 480890 & 775304 & 1227621 & 1445481 & 1130978 & 1407757 & 1578647 \\
\hline Valladolid & 333744 & 591204 & 982044 & 1320568 & 1211698 & 1328808 & 1507499 \\
\hline Guadalajara & 240702 & 425448 & 747935 & 856698 & 1035415 & 1219766 & 1413786 \\
\hline Puebla & 73893 & 208786 & 293718 & 415816 & 401839 & 396293 & 521004 \\
\hline Durango & 73993 & 189331 & 279129 & 326636 & 319689 & 409848 & 497012 \\
\hline Rosario & -- & 7985 & 140814 & 171140 & 172638 & 199619 & 217821 \\
\hline Oaxaca & 54854 & 105251 & 118302 & 151189 & 143958 & 157989 & 207710 \\
\hline Veracruz & 23657 & 60043 & 74203 & 15215 & 124798 & 138870 & 191847 \\
\hline Monterrey & 12936 & 43133 & 53942 & 69341 & 81698 & 88295 & 91388 \\
\hline Santander & 6674 & 31031 & 46900 & 60657 & 60657 & 68628 & 70732 \\
\hline Coahuila & 9934 & 14983 & 21940 & 26701 & 31510 & 37768 & 41943 \\
\hline Mérida & 12629 & 18591 & 19297 & 17510 & 17551 & 14416 & 18513 \\
\hline Mazapil & -- & 11489 & 12909 & 15336 & 13571 & 15800 & 17964 \\
\hline
\end{tabular}

*Las factorías de Córdoba y Orizaba operaban con pérdida.

Fuente: Deans-Smith (2014, p. 139).

Como pudo notarse la Renta del tabaco logró, mediante el estanco o monopolio, establecer una larga cadena distribuida por todo el virreinato que tenía por objetivo centralizar las ganancias de las ventas. En este sentido, puede decirse que la Renta del tabaco ejerció un monopolio sobre el comercio del tabaco, pues a pesar del contrabando, consiguió hacerse de ganancias mediante una siembra, manufactura y venta que la Renta monopolizó para su beneficio.

\section{Tendencias de consumo de tabaco en la factoría de Durango}

Como se muestra en la Figura 2, la factoría contaba con una administración general en la región, que se ubicó en la ciudad de Durango. Al mando de esta quedaron 13 partidos agregados, cada uno de estos tenía a su cargo a los fielatos agregados, que eran los poblados cercanos a los partidos. Mediante esta cadena de operaciones se abastecía a los estanquillos de la citada factoría y se dirigían las ganancias a la dirección general de México. Junto con las ganancias, la administración general regional de la capital de Nueva Vizcaya enviaba los "Pliegos de la Relación de consumos y valores de la Renta del tabaco de la factoría de Durango", que consistieron en los informes sobre las ventas ocurridas en toda la factoría. 
Estos documentos nos permiten conocer las tendencias de consumo en la región.

La Renta del tabaco ofrecía diversos productos a través de los estanquillos, de ahí la relevancia de observar las preferencias por parte de los consumidores. Mediante las ventas que tuvieron lugar en los estanquillos es posible observar las tendencias de consumo por parte de los habitantes de la factoría, lo cual permite un contraste con el consumo que se dio de manera clandestina, ya que, aunque no es posible conocer la magnitud de este último, si pueden notarse distintos patrones de consumo.

\section{Figura 2}

Mapa de la factoría Durango

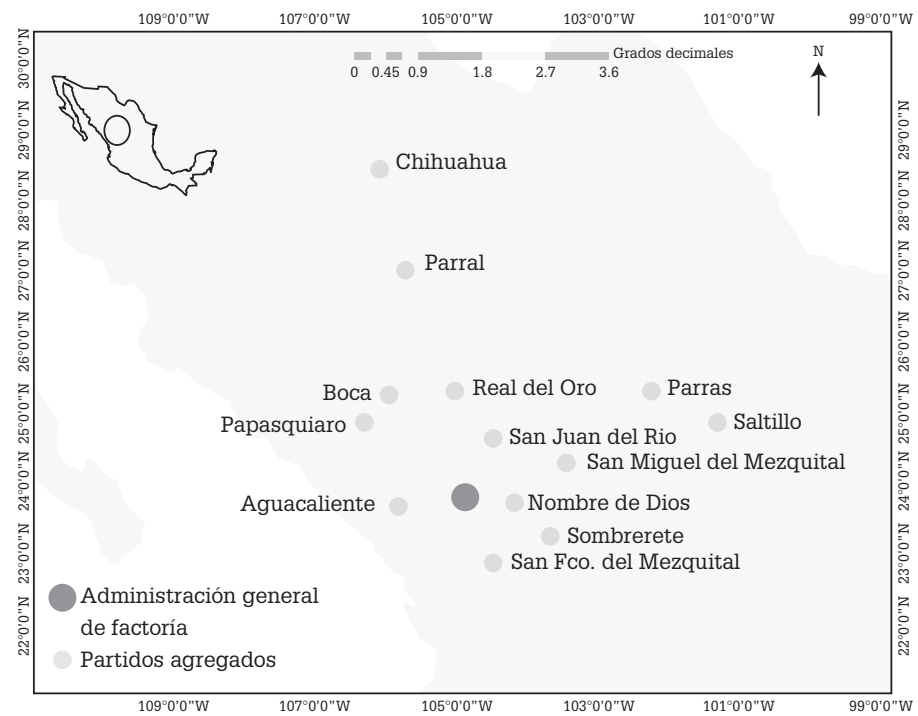

Fuente: AGN (Archivo Histórico de Hacienda, 1793, vol. 8, exp. 6).

De la fábrica de México llegaba a Durango tabaco en rama, en polvo o manufacturado en puros y cigarros. Los tercios de rama tenían el objetivo de brindar al consumidor la opción de labrar los puros o cigarros a su gusto y un peso aproximado de 150 libras. ${ }^{4} \mathrm{El}$ "polvo exquisito" era utilizado para inhalarse, procedía de La Habana y era almacenado en la Ciudad de México (Suárez, 1996, p. 121).

\footnotetext{
4 AGN (Indiferente virreinal, sección tabaco: 1808, caja 6389, exp. 27; 1808, caja 6664, exp. 33; 1808, caja 6665, exp. 30-33).
} 
Los puros y cigarros tenían calidades diferentes, la fábrica de México elaboraba puros que eran vendidos en paquetes llamados "papeles de a $6,8,12$ y 16". Las cantidades se referían al número de puros que contenían los paquetes y a la cantidad de tabaco de cada uno de estos, así, el "papel de a 6" contenía 6 puros y eran los que más contenían tabaco, los "papeles de a 16" contenían 16 pero eran los más delgados. ${ }^{5}$ Con las cajillas de cigarros ocurría algo semejante, existían de a 10, 11, 12, 13, 14 y 23, donde la cajilla de a 10 contenía 42 cigarros más gruesos y las de 23 , 60 más delgados; las cajillas se adquirían también por medio real.

La Tabla 2 se elaboró a partir de los informes de consumos y valores de los partidos. ${ }^{6}$ La razón de incluir los consumos del año 1808 es por la disponibilidad de las fuentes, ya que la mayoría de los informes de consumos y valores se encuentran dispersos y en ocasiones solo existen de manera mensual o semestral. ${ }^{7}$ Por último, otros informes no distan mucho de las proporciones de consumo de otros años, es decir, la tendencia de consumo queda clara sin necesidad de contrastar lo acontecido en otros años, pues en los pliegos de consumos y valores de otros años se observa también una tendencia similar.

\section{Ta.bla. 2}

Consumo en algunos partidos agregados a la factoría en 1808

\begin{tabular}{|lcccc|}
\multirow{2}{*}{\multicolumn{1}{c}{ Consumo en algunos partidos agregados a la factoría en 1808}} & \\
\cline { 4 - 5 } & Tercios & Papeles & Cajillas & Libras de polvo \\
& de rama & de puros & de cigarros & exquisito \\
\hline Chihuahua & 188 & 172533 & 17029694 & 113 \\
Parral & 00 & 400170 & 1087169 & 91 \\
Cuencamé & 00 & 33590 & 507673 & 00 \\
Nombre de Dios & 00 & 22401 & 415577 & 7 \\
Parras & 00 & 18639 & 423496 & 00 \\
Santiago & 00 & 12754 & 358229 & 00 \\
\hline
\end{tabular}

Fuente: Elaboración propia con base en los informes de valores y consumos de los partidos. ${ }^{8}$

5 En 1775 se podía comprar un paquete de cualquier calidad por medio real (McWatters, 1979, p. 239).

6 Los informes pueden encontrarse AGN (Fondo Indiferente virreinal, sección tabaco: caja 6389, exp. 27; caja 6664, exp. 33; caja 6665, exp. 30-33).

7 Aunque para el año 1808 no se encontraron los informes de todos los partidos, es el año donde se conjuntan el mayor número de informes.

8 AGN, Indiferente virreinal, sección tabaco: 1808, caja 6389, exp. 27; 1808, caja 6664, exp. 33; 1808, caja 6665, exp. 30-33 
Los ya citados "Pliegos de la Relación de consumos y valores de la Renta del tabaco de la factoría de Durango" contienen información sobre la cantidad de tercios de rama, de papeles de puros, de cajillas de cigarros y las libras de polvo exquisito que se vendieron durante todo el año en los distintos partidos. Más allá de analizar el volumen de consumo en cada partido, lo que interesa destacar son las tendencias; es decir, lo que los consumidores preferían, pues estas tendencias ayudarán a comprender las que se verán en el apartado relativo al contrabando del tabaco.

Una tendencia que comparten todos los partidos sin excepción es la preferencia por los cigarros seguida por los puros. El denominado polvo exquisito era adquirido a un precio elevado debido a que se importaba desde Cuba. La preferencia por inhalarlo fue una costumbre que mostraron los emigrantes peninsulares desde el siglo XVII (Céspedes, 1992, p. 47), y no los habitantes locales; de este modo, el polvo tenía una clientela limitada, tanto por el precio elevado como por ser una costumbre ajena a los habitantes locales. La preferencia por el "tabaco en humo", específicamente por el cigarro, no fue algo limitado a la factoría de Durango, sino dentro de toda la Nueva España. No por nada el cigarro es una invención novohispana de mediados del siglo XVI y que desde antes del establecimiento del monopolio se convirtió en la típica forma de utilización del tabaco (Céspedes, 1992, p. 46).

\section{Contrabando de tabaco en la factoría de Durango}

Comprender las tendencias dentro del comercio clandestino es también conocer la manera en que la Renta afrontaba el contrabando; en este sentido este trabajo cumple con un doble objetivo. Por un lado, se explica el proceso llevado a cabo en contra de los comerciantes, que aunque ya ha sido estudiado para el caso de otras regiones, como se verá a continuación, el combate al contrabando fue algo muy cambiante en las factorías. $\mathrm{El}$ segundo objetivo es complementar el panorama sobre las tendencias de consumo explicadas en el apartado anterior.

La ordenanza de 1768 reguló la actuación de la Renta ante la ilegalidad. Se optó por establecer un cuerpo de vigilancia que funcionó como una especie de policía conocida con el nombre de "el resguardo". Los visitadores, guardas, cabos y guardas patricios formaban el resguardo y eran responsables de perseguir a los contraventores, levantar un proceso sumario y, en su caso, aplicar el castigo correspondiente (Moreno, 2012 , p. 210). Sobre la intervención del resguardo la ordenanza solo establecía: 
Los puntos esenciales que deben tener muy presente para celar las introducciones de tabacos que se hacen, y que lo estén también de las circunstancias más requisitas, así del político gobierno de sus rondas, como las que deben practicar en sus registros; lo que han de ejecutar en sus aprensiones de tabacos, y las diligencias necesarias para la justificación de los contrabandos y defraudadores (Fonseca \& Urrutia, 1978, p. 481).

En su mayoría el apartado relativo al resguardo no describía más que generalidades y en ocasiones hasta obviedades, como cuando refería que el resguardo "debe distinguir el ilícito comercio de tabaco, qué sitios acostumbran a utilizar para sus introducciones y de qué medios y ardides se valen, deben tener una suma vigilancia y cuidado en la pesquisa pública y secreta de los contrabandos" (Fonseca \& Urrutia, 1978, p. 482). Además se advertía no caer en excesos y faltas de respeto.

De manera muy breve se indicaba el proceso a seguir cuando se encontrara a algún comerciante con tabaco no proveniente de la Renta, en estos casos, lo primero que tenía que hacerse es asegurar al defraudador y al contrabando "con las caballerías armas y demás bienes que se hallasen", llevarlo a la administración más próxima para dar cuenta al administrador y entregar el decomiso correspondiente. Si el monto del decomiso lo ameritaba se le embargarían los bienes al defraudador, y si fuera "preciso aprehender al comerciante se le dará su casa por cárcel, gobernándose en esto, la cantidad del delito". "En el caso que se encontraran siembras clandestinas el resguardo estaba obligado a investigar quién era el dueño del terreno, para poder tomar declaración y averiguar si es culpable o cómplice, al culpable le serían embargados sus bienes y las siembras serían arrancadas" (Fonseca \& Urrutia, 1978, p. 483).

Estas determinaciones tan generales difícilmente abarcaban las situaciones a las que el resguardo en la factoría se tenía que enfrentar, la ordenanza solamente determinó las pautas a seguir y la administración central prácticamente no tenía injerencia en el combate a la clandestinidad, lo cual conllevó a que en la práctica las autoridades de la factoría fueran las encargadas de dirigir al resguardo.

Cada factoría contó con características que hacían que el contrabando se llevara de manera diferente. La siembra del tabaco fue un factor que marcaría cambios significativos entre las factorías. Por ejemplo, como algunos de los territorios cercanos las factorías de Veracruz y Córdoba tenían las condiciones óptimas para la siembra ilegal de tabaco de gran calidad el resguardo se enfocaba en el combate de las siembras clandestinas. 
La nicotiana tabacum el tabaco de hoja clara, que era el que se sembraba en las zonas del actual estado de Veracruz, era el preferido de los consumidores. Los territorios de la factoría de Durango no presentaban las condiciones necesarias para la siembra de la Nicotiana tabacum; sin embargo las condiciones si permitían el crecimiento de dos tipos de planta silvestre, la nicotiana rústica conocida como "macuche" y la nicotiana glauca también llamado "tabaco cimarrón". El resguardo tendría que combatir la ilegalidad en una factoría que no contó con fábrica y no eran posibles los sembradíos de tabaco de hoja clara. A pesar de que el macuche y el tabaco cimarrón no se vendían en el estanco, o se vendía muy poco, pues los consumidores lo recibirían con desagrado, ${ }^{9}$ la siembra, manufactura o venta de ambas especies se vio también criminalizada por la Renta por lo que el contrabando de estas fue la constante en la factoría de Durango.

Don Carlos de Aguilar, distinguido real teniente de guardas de infantería, se encarga de relatar la manera en que combatía el contrabando en la factoría a su cargo. ${ }^{10}$ Cuando en 1767 avisado por el factor del tabaco de Durango, se le dijo que en el rancho Joaquín de Morga hay porción de "tabaco macuchi", el resguardo se dirigió al mencionado rancho, las diligencias siguientes quedaron también registradas por don Carlos y otros funcionarios. De manera similar pero en 1787, es directamente el teniente visitador de la Renta, Vicente de Herrera y Nieto, quien motivado por un secreto denuncio acudió a la casa de Paula de los Ríos en donde según la denuncia se labraban cigarros de contrabando. ${ }^{11}$

Las diligencias de reconocimiento del tabaco se dieron de manera constante por parte de las autoridades persecutoras, el reconocimiento del tabaco se enfocaba en conocer la calidad y cantidad del tabaco decomisado. El caso de la supuesta contrabandista Paula de los Ríos resulta muy ilustrativo para intentar explicar la importancia que tenía el reconocimiento del producto decomisado.

El 15 de septiembre de 1787 llegaron a casa de María Paula de los Ríos dos guardas de la Renta del Tabaco, catearon la casa de la señalada mediante "secreto denuncio" y encontraron un costal que contiene una porción de tabaco cernido, ante las indagaciones la acusada condujo a los miembros del resguardo hacia Josefa de Ibaraguen e Ignacio López a quienes señaló como responsables de la venta del tabaco encontrado en sus posesiones.

\begin{tabular}{l|l}
9 & AHED, 1816, cajón 17, exp. 39, s/f. \\
10 & AHED, 1767, cajón 24, exp. 43, s/f. \\
11 & AHED, 1787, cajón 25, exp. 112, s/f.
\end{tabular} 
Una vez en el lugar señalado los guardas iniciaron otro cateo ahora en la casa de los nuevos implicados, encontraron una olla de barro con porción de tabaco, Josefa de Ibaraguen al percatarse del descubierto arrojó el contenido de otra olla en una acequia cercana. Al haber encontrado contrabando en ambas casas los guardas procedieron a la aprensión de todos los señalados como contrabandistas y al embargo del tabaco clandestino.

Para reconocer la calidad del tabaco embargado el decomiso fue llevado a los almacenes de la factoría. El mismo día de la aprensión y en presencia del teniente visitador de la Renta, Vicente de Herrera y Nieto, dos peritos autorizados iniciaron el reconocimiento de un costal y una olla con porción de tabaco, ambos peritos lo "inspeccionan, reconocen y proceden a la prueba de fumado", los expertos concluyeron lo siguiente:

El tabaco del costal que fue el que se encontró a Paula es de la costa de tierra caliente que llaman macuchi y el de la olla es legítimo mezclado con el de la costa. Que este reconocimiento lo fundan en el gusto olor y parecer de dicho tabaco distinto enteramente al que se vende en el estanco. ${ }^{12}$

En posterior diligencia el peso del tabaco encontrado a Paula de los Ríos resultó de 12 libras 8 onzas, la olla de tabaco revuelto de "macuchi" y legítimo encontrada en casa del matrimonio de Ignacio López y Josefa de Ibaraguen resultó de dos libras. Respecto de la olla que según lo relatado por los guardas de la Renta la mujer tiró a la acequia y llenó con tabaco el recipiente "hasta la parte que demostró haber ocupado el tabaco", basándose en las marcas del recipiente el tabaco dio un peso de 2 libras.

La insistencia en conocer la calidad y cantidad del tabaco decomisado se explican con la lógica y normatividad que regulaban los procedimientos del resguardo. En el castigo a los contraventores pudo verse un claro ejemplo de lo mencionado, pues las penas a las que se harían acreedores aquellos que incurrieran en delitos relacionados con el contrabando consistían, entre otras más, en el pago del duplo valor y costos de la causa y pago del duplo del valor del tabaco decomisado, además los visitadores recibían una gratificación por el tabaco que lograban confiscar (Moreno, 2012, p. 213).

A pesar de la normatividad respecto del proceder en contra de los infractores existió una disparidad entre los diversos juicios en contra de los contrabandistas; es decir, no puede verse un completo procedimiento preestablecido para perseguir, juzgar y castigar a los contraventores. Tal

${ }_{12}$ AHED, 1787, cajón 25, exp. 112, s/f. 
falta de uniformidad no es de sorprender tomando en cuenta que el ejercicio del resguardo estaba subordinado a la organización de las factorías.

Conocer la calidad y cantidad del producto decomisado fue una de las pocas diligencias que se dio -aunque con algunas variantes- de manera uniforme en los diversos procesos por contrabando de tabaco. En 1767 el reconocimiento y peso del tabaco encontrado en esa ocasión en el rancho de don Joaquín de Morga se dio de manera similar al encontrado en 1787 a Paula de los Ríos.

A las 4:00 de la tarde del 29 de octubre de 1787 el factor de la Renta del tabaco de Durango, don Juan Bautista de Ugarte es avisado que en el rancho de Joaquín de Morga hay porción de tabaco serrano llamado "macuchi", los guardas acuden al rancho que el mismo factor les señaló. El denuncio resultó cierto, la orden del factor había sido la siguiente:

Se ha mandado a los guardas de la Renta pasen al expresado rancho y recogiendo todo el tabaco que en el hallaren, cateada y registrada para ello toda la casa, lo conduzcan y entreguen todo en la factoría para que en ella se reconozca, tome razón de su especie y cantidad, así mismo pongan preso a Joaquín de Morga en la cárcel pública. ${ }^{13}$

Una vez cumplida la orden, ya en la "factoría y casa del estanco", ${ }^{14} \mathrm{se}$ procedió al reconocimiento y peso del tabaco. En esta ocasión no se hace mención directa de peritos aunque el proceder de la diligencia indica que probablemente sí se trataba de expertos en la materia.

En presencia del factor el reconocimiento fue realizado por el fiel de almacenes en conjunto con Justo de Lara de quien solo se dice fue nombrado para tal diligencia. Los responsables de la tarea solicitada iniciaron inspeccionando un tercio cerrado con el abrigo o figura de pescado o sal de espumilla y cuatro costales, después de dejar constancia del peso de cada uno de ellos concluyeron lo siguiente:

El tercio cerrado y los dos primeros costales es todos tabaco serrano en greña que llaman chicharrón, las cuarenta libras del tercero costal es tabaco de Tepic y las veinte libras del cuarto y último que está ya desecho es tabaco revuelto de ambos chicharrón y Tepic. ${ }^{15}$

\footnotetext{
13 AHED, 1787, cajón 25, exp. 112, s/f.

14 Almacenes generales de la factoría.

15 AHED, 1767, cajón 24, exp. 43, s/f.
} 
Tanto en el decomiso hecho a Paula de los Ríos y a Joaquín de Morga resalta el hecho de que el tabaco haya sido de tipo silvestre el "distinto al que se vende al estanco" y en menor medida el "legítimo"; es decir, el que se vende en el estanco, destaca también que en ambos comisos se diera el caso de encontrar mezclado el tabaco legítimo con el ilegítimo.

El denominado "tabaco de Tepic" se refería a la especie Nicotiana Tabacum, ya que esa región contaba con las condiciones climáticas necesarias para la siembra de esa especie de tabaco, incluso en 1771 la Renta del Tabaco, ante la escases de la solanácea autorizó la siembras en esa región; sin embargo, el mismo año fueron nuevamente prohibidas (Amerlinck, 1988, p. 112). Tomando en cuenta que la Renta relegó las zonas para cultivo de tabaco hacia algunas regiones del actual estado de Veracruz, la localidad de Tepic -que perteneció a la factoría de Guadalajara- fue probablemente el territorio más cercano a la factoría de Durango en donde podía conseguirse el tabaco de hoja clara; en este caso de manera ilegal como indican los expedientes de comiso.

Por orden del virrey de la Nueva España -el marqués de Croix- se indicó como castigo a los comerciantes de tabaco no autorizado por la Renta la pena del pago del duplo del valor del tabaco decomisado. ${ }^{16}$ Este ordenamiento tuvo que adecuarse para el caso del decomiso hecho a Paula de los Ríos en que se concluyó que las 3 libras y 8 onzas del tabaco encontrado en las propiedades de la acusada "se considera invendible y no cabe reducirse a dinero", pero que para la operación (la de calcular el duplo) se procedió a una suma acorde con el peso del tabaco y no con un cálculo del duplo como marcaba la normatividad, ya que al no tener valor, no había cantidad sobre la cual hacer la respectiva suma.

Los esfuerzos por el resguardo para combatir el contrabando se enfocaron en perseguir un tabaco que ni si quiera se vendía en el estanco, pues ante la falta de consumidores, la Renta del tabaco se rehusó a vender el tabaco serrano. Lo que las autoridades intentaban conseguir al combatir el comercio del tabaco silvestre fue evitar la competencia de un tabaco que aunque de sabor desagradable podría ser conseguido a un precio muy bajo o también era posible que el consumidor los sembrara fácilmente.

Al no poder sacar provecho del tabaco silvestre, la Renta procedió a deshacerse de manera particularmente ejemplar del decomiso, para de ese modo mandar un mensaje a sus competidores ilegales. Nuevamente el delito de Paula de los Ríos nos proporciona una descripción al respecto. En los almacenes generales una vez terminada la diligencia en la que se calculaba lo que debían pagar los infractores y "en presencia de los seño-

${ }_{16} \mid$ AHED, 1787, cajón 25, exp. 112, s/f. 
res factor y contador y otros administradores de la renta", se sacaron las 21 libras 8 onzas de tabaco "macuchi" hasta entonces resguardados en el almacén y fueron llevadas a "espaldas de la casa donde se encontraban", a un callejón donde se encontraba una hoguera, donde el macuche fue reducido a cenizas. La misma suerte corrió el contrabando de Joaquín de Morga en el que se procedió a "mandar sacar de los almacenes, donde se halla depositado el tabaco de este decomiso reconocido primero y pesado [...] puesto en la calle para que se queme todo hasta reducirse a cenizas. ${ }^{17}$

El contrabando de tabaco fue algo que en realidad la Renta nunca pudo controlar. Los pequeños comerciantes fueron siempre motivo de preocupación para las autoridades a tal punto que en más de una ocasión se dudó en establecer el estanco por la reacción que los numerosos comerciantes pudieran tener. Después de establecido el estanco, en la factoría de Durango se seguían labrando puros y cigarros y existían sembradíos no permitidos por la regulación de la Renta. Aunque los sembradíos de tabaco que el clima de la región permitía eran de otro tipo al que el estanco vendía, el llamado tabaco "macuchi" y "cimarrón" fueron la materia prima que alimentó a los contrabandistas.

Un estudio sobre las siembras clandestinas en la región de Papantla argumenta que las autoridades veían al contrabando con indiferencia e incluso que era tolerado (Moreno, 2012, p. 211), posiblemente esto aplicaba para toda la Nueva España. Como ya se había mencionado, el consumo de tabaco en la factoría se daba en forma generalizada, donde hasta en los más alejados fielatos se efectuaban considerables ventas acorde con la relativamente baja densidad de población. El popularizado consumo se extendió también sobre el tabaco no procedente del estanco, que aunado a la inmensidad del territorio, convirtió al contrabando en un gran problema para la Renta que el resguardo sería incapaz de erradicar.

Las fuentes utilizadas en este apartado son de utilidad para saber la manera en que la Renta afrontaba el contrabando y para conocer sobre el consumo clandestino. Pero, dado el carácter de ilegalidad, este no puede ser contabilizado, ya que no existe un registro que de algún modo pueda medir el comercio clandestino, pues solo sabe de los casos en los que el infractor lograba ser atrapado, en las cuales solo hay menciones que refieren al contrabando como una práctica frecuente. Aun así, se visualiza un elevado consumo de tabaco fuera de lo que el estanco regulaba.

17 AHED, 1767, cajón 24, exp. 43, s/f. 


\section{Conclusiones}

La creación de la factoría de Durango fue parte de la estrategia de la Corona para que, mediante la monopolización del comercio del tabaco, se pudieran aumentar las recaudaciones en beneficio de la metrópoli. Desde el punto de vista de estos fines, la factoría de Durango estuvo en funciones en el periodo que va de 1778 a 1813, pues solo durante estos años se consiguió enviar las ganancias relativas de las ventas a la administración central. Para cumplir con la función para la que fue creada, la factoría tuvo que operar con la problemática del contrabando a cuestas.

El contrabando fue un problema arraigado con generalidad en la Renta del tabaco dentro de todo el virreinato. Basta recordar que, como se mencionó en el primer apartado, la gran cantidad de modestos tabaqueros -quienes en muchas ocasiones dependían de la venta de los diversos productos de tabaco para su sustento fueron los que hicieron titubear a las autoridades para establecer el estanco.

En la referida factoría se vio que en los casos de decomiso el contrabando incluyó al denominado tabaco "macuhe" y "cimarrón". Al ser estas plantas silvestres, ocurrió que los vendedores clandestinos tenían este tipo de planta en sus propias casas.

Por otro lado, los consumidores podían adquirir en los estanquillos tabaco en rama, manufacturado en puros y cigarros y en polvo. De estas formas se destacó el consumo de puros y cigarros, y dentro de estos dos -al menos para el caso de la factoría de Durango- podría decirse que existió una marcada preferencia por el consumo de "tabaco en humo".

En el comercio clandestino, se repetía la misma tendencia, pero en este caso con las particularidades de la región y no bajo los ordenamientos del estanco. Se observó cómo el resguardo combatía la ilegalidad, donde la constante era encontrar contrabando de otra clase de tabaco a la que se vendía en los estanquillos -particularmente "macuche" y "cimarrón"-. El tabaco de hoja clara, que era el comerciado por la Renta y que procedía de algunas regiones del actual estado de Veracruz, no podía desarrollarse en los territorios pertenecientes a la factoría de Durango, pues las condiciones climatológicas no lo permitían, caso contrario a las referidas plantas silvestres, pues las condiciones del territorio eran las idóneas para la siembra de este tipo de tabaco. El macuche y Cimarrón fueron descritos por las autoridades como un tabaco de sabor desagradable y que repugnaba a los compradores. Por tal motivo este tipo de planta no contó con valor alguno para la Renta. No obstante, su venta fue criminalizada al representar una competencia para los estanquillos. 
El uso del macuche y cimarrón obedeció a que podía ser adquirido a un bajo o a ningún costo, pues era una planta silvestre. La repugnancia hacia este tabaco de esta clase no parece haber sido compartida cuando se trataba de un consumo "clandestino", ya que existió un elevado consumo de estos cigarros. Por último, debe recordarse que mezclar tabaco silvestre con el "legítimo", fue una práctica común. Una de las razones es que los fumadores deseaban suavizar el fuerte sabor del tabaco silvestre.

\section{Archivos}

AGN Archivo General de la Nación.

AHED Archivo Histórico del Estado de Durango.

\section{Referencias bibliográficas}

Amerlinck, M. C. (1988)

Historia y cultura del tabaco en México. México: Tabamex/Secretaría de Agricultura y Recursos Hidráulicos.

Céspedes del Castillo, G. (1992)

El tabaco en Nueva España. Madrid: Real Academia de la Historia.

Deans-Smith, S. (2014)

Burócratas, cosecheros y trabajadores: la formación del monopolio del tabaco en la Nueva España borbónica. México: Instituto Mora.

Fonseca, F. \& Urrutia, C. (1978)

Historia general de real hacienda: por orden del virrey, conde de Revillagigedo (Volumen 2). México: Departamento de Gráficas de la Secretaría de Hacienda y Crédito Público. (Trabajo original publicado en 1850).

Hernández, J. (2011)

Entre el liberalismo radical y la necesidad: los debates en torno al monopolio estatal del tabaco en México, 1821-1824. América Latina en la Historia Económica (36), 65-91. Recuperado de http://www.scielo.org. $\mathrm{mx} /$ scielo.php?script=sci_arttext\&pid=S1405-22532011000200004

Marichal, C. (1999)

La bancarrota del virreinato, Nueva España y las finanzas del imperio español, 1780-1810. México: El Colegio de México/Fideicomiso Historia de las Américas/Fondo de Cultura Económica.

McWatters, D. L. (1979)

The royal tobacco monopoly in bourbon México, 1764-1810. Tesis de doctorado no publicada. Universidad de Florida, EE.UU. Recuperado de https://archive.org/details/royaltobaccomono00mcwa

Moreno Coello, G. (2012)

Alcaldes mayores y subdelegados frente a la siembra clandestina de 
tabaco: Papantla, 1765-1806. América Latina en la Historia Económica, 19 (3), 206-234. Recuperado de http://www.scielo.org.mx/scielo. php? script=sci_arttext\&pid=S1405-22532 012000300007

Sánchez, E. (2010)

Una modernización conservadora: el reformismo borbónico y su impacto sobre la economía, la fiscalidad y las instituciones (pp. 288-336). En C. G. Ayluardo (Coord.), Las reformas borbónicas, 1750-1808. México: Fondo de Cultura Económica.

Suárez Argüello, C. E. (1996)

Camino real y carrera larga. La arriería en la Nueva España durante el siglo XVIII. México: Centro de Investigaciones y Estudios en Antropología Social. 